\title{
SAHIPLIK YAPISI VE AR-GE HARCAMALARI: BORSA İSTANBUL ÖRNEĞİ
}

\author{
Dr. Mesut DOĞAN \\ Afyon Kocatepe Üniversitesi, Bayat MYO,(mesutdogan07@gmail.com) \\ Doç. Dr. Murad TIRRYKİĞLUU \\ Afyon Kocatepe Üniversitesi, İ̈BF, (tiryakioglum@gmail.com)
}

\begin{abstract}
ÖZET
$B u$ çalışmanın amacı sahiplik yapısının AR-GE harcamaları üzerindeki etkisini incelemektir. Başka bir ifade ile araştırmada; sahiplik yoğunlaşmasının, kurumsal yatırımcı sahipliğinin ve yabancl yatırımc sahipliğinin AR-GE uygulamaları üzerindeki etkisi tespit edilecektir. Çalışmada 2009-2015 yılları arasında Borsa İstanbul'a kayıtlı 112 imalat sanayi firmasının verileri kullanılmıstır. Yapılan analizler sonucunda yabancı yatırımcıların daha düşük AR-GE harcamalarına sahip olduğu bulunmuştur. Bu durum; yabancı yatırımcılar kendi ana ülkelerindeki ve/veya diğer gelişmiş ekonomilerdeki teknolojik avantajları kullanmaları ile açılanabilmektedir.
\end{abstract}

Anahtar Kelimeler: AR-GE, İnovasyon, Sahiplik Yapisı.

\section{OWNERSHIP STRUCTURE AND R\&D SPENDING: EVIDENCE FROM BORSA ISTANBUL}

\begin{abstract}
This paper examines the effects of ownership structure on firms' $R \& D$ spending. In other words, this paper seeks to examine the effect of ownership concentration, institutional ownership and foreign ownership on the $R \& D$ spending practices. It is used a sample of 112 Turkish manufacturing firms listed Borsa Istanbul from 2009-2015. It is found that firms with foreign ownership have lower $R \& D$ spending.Foreign investors would utilize technological advantages at their home countries and/or other developed economies.
\end{abstract}

Keywords: R\&D, Innovation, Ownership Structure. 


\section{Giriş}

İnovasyon, daha önce elde edilmiş olanlardan daha kaliteli ve/veya daha düşük maliyetli bir ürün üretmek için kaynakların geliştirildiği bir süreçtir (O'Sullivan, 2000). Buradaki temel amaç, piyasadaki rakipler üzerinde rekabetçi bir avantaj elde etmek veya korumaktır. İnovasyon, ekonomik kalkınma ve şirketlerin büyümesinin anahtarı olarak kabul edilmektedir. İnovasyon, firmaların dış pazarlar da dahil olmak üzere yeni pazarlara girme kabiliyetlerini de etkilemektedir (Cebula \& Rossi, 2015: 297).

Birçok araştırmacı sürekli inovasyonun önemini ve özellikle şirketlerin büyümesinde araştırma ve geliştirmenin (AR-GE) rolünü vurgulamıştır (Porter, 1991; Zahra \& Covin, 1995). Bununla birlikte çok sayıda araştırmacı sahiplik yapısının ve sahiplik yapısı türlerinin AR-GE harcamalarına etkisi üzerine araşırmalar yapmışlardır (Graves 1988; Kochhar \&David 1996; De Mello 1997; Molas-Gallart \& Tang 2006; Minetti, Murro \& Paiella 2012; Aghion, Reenen \& Zingales 2013). Yapılmış olan çalışmalarda ülkelere ve örnekleme göre değiştiği ve farklı yönde sonuçların tespit edildiği görülmüştür.

Şirketin önemli bir oranda sermaye payını elinde bulunduran hissedar işletmenin alacağı kararlarda söz sahibidir. Başka bir ifade ile yönetimin alacağı kararlarda etkin bir rol üstlenebilir. Bununla birlikte büyük hissedarlar işletmenin pazarlama satış, üretim, dağıtım politikaları, yatıım kararları, finansman ve temettü politikaları ile alınacak kararlarda da doğrudan etkilidir. Azınlık ortaklar ile kontrol gücünü ellerinde bulunduran ortaklar arasında bir temsilcilik sorunu ortaya çıkması kaçınılmazdır. Bununla birlikte yabancı yatırımcıların elinde bulundurduğu sermaye oranı firmaların halka açıklık oranını dolayısıyla sahiplik yapısını etkilemektedir. Yabancı yatırımcılar, kurumsal yönetim mekanizmalarının yetersiz olduğu gelişmekte olan ülkelere hâkim ortak olma yolunu tercih ederek hukuksal boşluğu doldurmaktadır (La Porta, Lopez-De-Silanes \& Shleifer, 1999). Kurumsal yatırımcilar ise diğer yatırımcı türlerine göre kıyaslandığında önemli seviyede ortaklığa sahip olmasından ve ortakların uzun dönemli menfaatlerini yönetmede üst yönetimi etkilemeye çalışmasından dolayı şirket yönetim kararları ile daha ilgilidir (Holderness, Kroszner \& Sheehan, 1988; Brickley, Lease \&Smith, 1998). Sonuç olarak üç yatırımcı türü de yönetim kararlarını ve dolayısıyla AR-GE faaliyetlerini etkileyebilmektedir. Özellikle söz konusu yatırımcıların kısa vadede kazanç sağlama isteği veya uzun vadede sağlıklı büyüyerek kazanç sağlama isteği ARGE aktivitelerini de etkilemektedir.

Bu çalışmanın amacı sahiplik yapısının AR-GE harcamaları üzerindeki etkisini tespit etmektir. Başka bir ifade ile araştırmada; sahiplik yoğunlaşmasının, kurumsal yatırımcı sahipliğinin ve yabancı yatırımcı sahipliğinin AR-GE harcamaları üzerinde etkisinin olup olmadığ 1 , varsa hangi yönde olduğu belirlenecektir. Araştırmada 2009-2015 yılları arasında BİST Sınai Endeksi'nde 112 firmanın verilerinden yararlanılmıştır. Araştırma Türkiye'de yapılan ilk çalışma olması bakımından önem taşımaktadır.

$\mathrm{Bu}$ makalenin geri kalan kısmı aşağıdaki şekilde düzenlenmiştir. İkinci bölümde literatür taraması yapılmış ve hipotezler geliştirilmiştir. Üçüncü bölümde ampirik testler için değişkenler tanıtılarak çalışmanın modeli tasarlanmıştır. Dördüncü bölümde çalışmanın bulgularına yer verilmiştir. Son bölümde ise sonuç ve özet sunulmuştur. 


\section{Literatür Taraması ve Hipotezler}

Sahiplik yapısı ile ilgili birçok çalışma yapılmıştır. Yapılmış olan çalışmalar incelendiğinde Barnhart \& Rosenstein (1998);Kuznetsov \& Muravyev (2001); Bhagat \& Black (2002); Oxelheim \& Randøy (2003);Andersson, Nordwall \& Salomonsson (2004); Mak \& Kusnadi (2005); Beiner vd. (2006); Cho \& Kim (2007); Lam \& Lee (2008); Wang \&Clift (2009); Sueyoshi, Goto \& Omi (2010);Elsayed (2011);Fauzi \&Locke (2012); Vo \& Phan (2013) gibi yazarlar sahiplik yapısının finansal performans üzerindeki etkisini incelemişlerdir. Bu çalışmaların dışında Chauvin \& Hirschey (1993); Sougiannis (1994); Abrahams \& Sidhu (1998); Chan, Lakonishck \& Sougiannis (2001); Chambers, Jennings \& Thompson (2002); AlHorani, Pope \& Stark (2003); Eberhart, Maxwell \& Siddique (2004); Lev, Sarath\& Sougiannis (2005); Krasnikov \& Jayachandran (2008); Ahmed \& Jinan (2011); Sharma (2012); Ghaffar \& Khan (2014) gibi yazarlar ise AR-GE harcamaları ile firma performansı arasındaki ilişkiyi analiz etmişlerdir. Ancak sahiplik yapısının AR-GE harcamaları üzerindeki etkisini inceleyen çalışmaların sayısı oldukça azdır. Söz konusu çalışmalar aşağıda özetlenmiştir.

Zeng \& Lin (2011) Çin'de faaliyette bulunan 780 firma açısından 2000-2005 yıllarının verilerini kullanarak yaptıkları çalışmada AR-GE harcamaları ile firma büyüklüğü, kaldıraç oranı, stok ve duran varlık yoğunluğu arasında negatif bir ilişki buna karşın varlık karlılığı ile anlamlı olmayan bir ilişki bulmuşlardır. Ayrıca sermaye yapısı yoğunlaşması arttıkça ARGE harcamaları yoğunluğunun azaldığını tespit etmişlerdir. Minetti, Murro \& Paiella (2012) sahiplik yapısının yenilikçilik üzerindeki etkisini İtalya'da faaliyette bulunan 20000 üretici üzerinde test etmişlerdir. Çalışmaların sonucunda sermaye yoğunlaşmasının firma yenilik faaliyetlerini özellikle AR-GE çabalarını olumsuz bir şekilde etkilediğine yönelik kanıtlar sunmuşlardır. Benzer şekilde Rossi \& Cebula (2015) 2005-2013 yılları arasında İtalya borsasına kayıtlı 363 firma açısından sahiplik yapısının AR-GE harcamalarına etkisini araştırmışlardır. Çalışmalarının sonucunda AR-GE harcamaları ile mülkiyet yoğunlaşması arasında negatif bir ilişki buna karşın kurumsal yatırımcı sahipliği ile AR-GE harcamaları arasında pozitif ve istatistiksel olarak anlamlı bir ilişkinin varlığını ortaya koymuşlardır. Ayrıca çalışmada kontrol değişken olarak kullandıkları firma büyüklüğü ve yaşı ile AR-GE harcamaları arasında pozitif ancak kaldıraç oranı ile AR-GE harcamaları arasında negatif bir ilişki bulmuşlardır. Buna karşın Hill \& Snell (1988); Baysinger, Kosnik \& Turk (1991) ise sermaye yapısı yoğunlaşması ile AR-GE harcamaları arasında pozitif bir ilişki bulmuşlardır. Buradan hareketle araştırmada şu hipotezler geliş̧tirilmiştir.

\section{$H_{1}$ : Sermaye yapısı yoğunlaşması AR-GE harcamaları üzerinde etkilidir.}

\section{$H_{0}$ : Sermaye yapısı yoğunlaşması AR-GE harcamaları üzerinde etkili değ̈ildir.}

Eng \& Shackell (2001) yaptıkları araştırmalarında kurumsal yatırımcı sahipliği ile ARGE harcamaları arasında pozitif bir ilişkinin varlığını ortaya koymuşlardır. Benzer şekilde Bushee (1998) kurumsal yatırımcı sahipliğinin yüksek olduğunda, yöneticilerin kazançlarındaki düşüşü tersine çevirmek için AR-GE harcamalarını kesme olasılığının düşük olduğuna yönelik bulgular ortaya koymuştur. Aghion, Reenen \& Zingales (2013) ABD'de faaliyette bulunan halka açık şirketler açısından kurumsal yatırımcı sahipliğinin yenilik faaliyetlerini artırdığını belirtmişlerdir. Ancak Graves \& Waddock (1990) yenilik faaliyetleri ile kurumsal yatırımcı 
sahipliği arasında negatif kanıtlar ortaya koymuşlardır. Brossard, Lavigne \& Sakinc (2013) yüksek yeniliğine sahip büyük Avrupa şirketlerinin verilerinden yararlanarak sahiplik yapısı ile yenilik aktiviteleri arasındaki ilişkiyi incelemişlerdir. Çalışmalarının sonucunda daha yüksek AR-GE harcamaları oranına sahip firmalarda kurumsal yatırımcıların hakim olduğunu tespit etmişlerdir. Ancak kısa vadede karlılıklarını yükseltmek isteyen aceleci kurumsal yatırımcılarda bu oranının daha düşük olduğunu bulmuşlardır.

Bu bilgiler ışı ğında aşağıdaki hipotezler geliştirilmiştir.

$H_{2}$ : Kurumsal yatırımcı sahipliği AR-GE harcamaları üzerinde etkilidir.

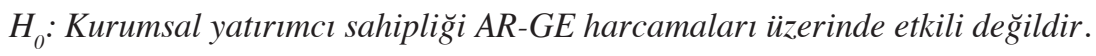

Zhang vd. (2007) yabancı yatırımcıların önemli oranda ortaklıkları olduğunda gelişen ekonomilerde ve uluslararası ortak girişimlerde AR-GE aktivitelerini desteklemeye daha meyilli olduklarını ifade etmişlerdir. Geçmiş araştırmalar yabancı yatırımcıların çok uluslu şirketlerden yerel şirketlere doğrudan teknoloji transferini kolaylaştırdığını göstermektedir (Chen \& Bolon, 1993; Teng \& Yi, 2014). Doğrudan yabancı yatırımın gelişmekte olan ülkelerdeki teknolojik değişimlerin önemli bir aracı olduğunu ve yabancı yatırım şirketlerinin ev sahibi ülkedeki mevcut bilgi stokunu geliştirmesi beklenmektedir (De Mello, 1997). Bunun neticesinde ise yabancı yatırımcı sahipliğinin AR-GE çıktılarına pozitif bir etki yapmaktadır (Cheung \& Lin 2004; Buckley, Wang \& Clegg, 2007; Choia, Leeb \& Williams, 2011).

Birçok yazar yabancı yatırımcıları teknolojinin temel katkı sağlayanı olarak ortaya çıktığını vurgulamasına rağmen Pearce (1989) yurtdışı AR-GE yatırımlarının temel işlevini üretim naklini kolaylaştırmak amacıyla yerel koşullarda gelişen bilgiye ve mevcut teknolojiye uyum sağlamak olduğunu ileri sürmüştür. Buna karşın Teng \& Yi (2014) Çin'de 2005-2007 yılları arasında faaliyette bulunan 359,874 firmanın sahiplik yapısının AR-GE aktiviteleri üzerindeki etkisini incelemişlerdir. Geliştirilen modeller sonucunda yabancı yatırımcı sahipliği ile AR-GE harcamaları arasında negatif bir ilişki bulmuşlardır. Benzer şekilde Gassmann \& Zedtwitz (1999) uluslararası yenilik süreçlerinin çokuluslu şirket ile yerel ortak arasındaki potansiyel işbirliği tarafından belirlendiğini ve AR-GE faaliyetlerinde önemli teknolojik varlıklar ve işbirliği olmadan, çok uluslu bir şirket AR-GE'yi kendi ülkesinde yoğunlaştırmayı tercih ettiğini belirtmişlerdir. Bu bağlamda aşağıdaki hipotezler geliştirilmiştir.

$H_{3}:$ Yabancı yatırımcı sahipliği AR-GE harcamaları üzerinde etkilidir.

$H_{0}$ : Yabancı yatırımcı sahipliği AR-GE harcamaları üzerinde etkili de ğildir.

\section{Metodoloji}

Araştırmanın bu bölümünde çalışmanın amacına, veri setine, değişkenlere ve yönteme ilişkin bilgiler verilmiştir.

\subsection{Araştırmanın Amacı}

Bu çalışmanın amacı; sahiplik yapısının AR-GE harcamaları üzerindeki etkisini tespit etmektir. Başka bir ifade ile araştırmada; sahiplik yoğunlaşmasının, kurumsal yatırımcı 
sahipliğinin ve yabancı yatırımcı sahipliğinin AR-GE harcamaları üzerinde etkisinin olup olmadığ 1 , varsa hangi yönde olduğu belirlenecektir. Bu amaçların dişında firma karlılığı, büyüklüğü, yaşı, borç seviyesi, duran varlık ve stok seviyesi ile AR-GE harcamaları arasındaki ilişki de ortaya çıkarılacaktır.

\subsection{Araştırmanın Veri Seti}

Bu araştırmada 2009-2015 yılları arasında BİST Sınai Endeksi'nde 112 firmanın verilerinden yararlanılmıştır. Bununla birlikte elde edilecek bulguların genellenebilirliği için ve kullanılacak mali tabloların tekdüzeliğin sağlanması açısından çalışmada sadece BİST Sınai Endeksi'nde yer alan firmalar kullanılmıştır. Analiz kapsamında incelenen firmalara ait finansal veriler Finnet mali analiz programından elde edilmiştir. Sahiplik yapısına ilişkin bilgiler ise Merkezi Kayıt Kuruluşu'ndan (MKK) temin edilmiştir.

\subsection{Değişkenler}

$\mathrm{Bu}$ araştırmada toplam 10 adet değişken kullanılmıştır. Bu değişkenlerden 1 tanesi bağımlı değişken, 3 tanesi ortaklık yapısına ilişkin bağımsız değişkenler ve 6 tanesi ise kontrol değişkenlerdir. Araştırma kullanılan değişkenler Tablo 1'de gösterilmiştir.

Tablo 1: Analizlerde Kullanılan Değişkenler

\begin{tabular}{|c|c|}
\hline & Tanımlamalar \\
\hline AR-GE Yoğunluğu (ARGE) & $\begin{array}{l}\text { AR-GE harcamaları faaliyet giderlerine } \\
\text { bölünmüştür. }\end{array}$ \\
\hline Sermaye Yapısı Yoğunlaşması (SPAY) & $\begin{array}{l}\text { En büyük beş ortağın sermaye tutarı, toplam } \\
\text { sermayeye bölünmüştür }\end{array}$ \\
\hline Kurumsal Yatırımcı Sahipliği (KPAY) & $\begin{array}{l}\text { Kurumsal yatırımcıların elinde bulundurduğu } \\
\text { sermaye tutarı, toplam sermayeye bölünmüştür. }\end{array}$ \\
\hline Yabancı Yatırımcı Sahipliği (YPAY) & $\begin{array}{l}\text { Yabancı yatırımcıların elinde bulundurduğu } \\
\text { sermaye tutarı, toplam sermayeye bölünmüştür }\end{array}$ \\
\hline Borç Yapısı(BORC) & Toplam varlık içerisinde borç oranıdır. \\
\hline Firma Büyüklüğü (BUYUK) & Toplam varlıkların doğal logaritmasıdır. \\
\hline Firma Yaşı $(Y A S)$ & $\begin{array}{l}\text { Firmaların kuruluş yılı ile cari yıl arasındaki } \\
\text { farktır. }\end{array}$ \\
\hline Firma Karlılığ & Net kar toplam varlıklara bölünmüştür. \\
\hline Duran Varlık Yoğunluğu (DURAN) & Duran varlıklar toplam varlıklara oranlanmıştır. \\
\hline Stok Yoğunluğu (STOK) & Stoklar toplam varlıklara oranlanmıştır. \\
\hline
\end{tabular}




\subsection{Araştırmanın Yöntemi}

Araştırmada kullanılan veriler dengeli panel veri özelliği göstermektedir. Çalışmada kullanılan veriler Stata 11.0 programından yararlanarak çözümlenmiştir. Çalışmada öncelikle tanımlayıcı istatistiklere, t-testine ve korelasyon analizine yer verilmiştir. Değişkenlerin birim kök analizi için Fisher ADF Kök Testi kullanılmıştır. Çalışmada, değişen varyans, otokorelasyon veya birimler arası korelasyonun (yatay kesit bağımlılı̆̆ının) varlı̆̆ına karşı dirençli olduğu için ve $\mathrm{T}<\mathrm{N}$ (yıl küçüktür gözlem sayısı) durumunda uygulanabildiğinden Beck-Katz (1995) tarafından geliştirilen dirençli tahminci kullanılmıştır. Literatürde yer alan çalışmalar referans (Tao \& Lin, 2011; Teng \& Yi, 2014; Cebula \& Rossi, 2015) alınarak aşağıdaki model geliştirilmiştir.

$$
A R G E_{i t}=\alpha+\alpha_{1} S P A Y+\alpha_{1} K P A Y+\alpha_{1} Y P A Y+\Sigma_{k} \wedge_{k}+K O N T R O L_{i t+} \varepsilon_{i t}
$$

\section{Araştırmanın Bulguları}

Çalışmanın bu bölümünde tanımlayıcı istatistiklere, T-testi sonuçlarına ve sahiplik yapısı ile AR-GE harcamaları arasındaki ilişkiyi gösteren dirençli tahminci sonuçlarına yer verilmiştir.

\section{Tablo 2: Tanımlayıcı İstatistikler}

\begin{tabular}{lcccccc}
\hline & Ort. & Med. & S.Sap. & Min & Max & G.Say. \\
\hline Değişkenler & & & & & & \\
\hline AR-GE Yoğunluğu & 0,028 & 0,064 & 0,484 & 0,00 & 0,32 & 784 \\
\hline Sermaye Yapısı Yoğunlaşması & 0,714 & 0,744 & 0,174 & 0,14 & 1,00 & 784 \\
\hline Kurumsal Yatırımcı Sahipliği & 0.247 & 0,194 & 0.214 & 0,00 & 0.98 & 784 \\
\hline Yabancı Yatırımcı Sahipliği & 0,075 & 0,021 & 0,159 & 0,00 & 0,98 & 784 \\
\hline Borç Yapısı (BORC) & 0,428 & 0,422 & 0,213 & 0,02 & 0,88 & 784 \\
\hline Firma Büyüklü̆̆̈̈ $(B U Y U K)$ & 19,79 & 19,62 & 1,389 & 16,89 & 23,8 & 784 \\
\hline Firma Yaşı (YAS) & 40,81 & 42,00 & 11,60 & 12,00 & 80,0 & 784 \\
\hline Firma Karlılı̆̆ı (KAR) & 0,048 & 0,044 & 0,093 & $-0,52$ & 0,57 & 784 \\
\hline Duran Varlık Yoğunluğu $(D U R A N)$ & 0,481 & 0,480 & 0,181 & 0,05 & 0,99 & 784 \\
\hline Stok Yoğunluğu (STOK) & 0,151 & 0,134 & 0,098 & 0,00 & 0,72 & 784 \\
\hline
\end{tabular}

Tablo 2'de ampirik analizlerde kullanılan bağımlı ve bağımsız değişkenlere ilişkin tanımlayıcı istatistik sonuçları gösterilmiştir. BİST sınai endeksinde faaliyet gösteren ve analiz kapsamında incelenen firmaların faaliyet giderleri içerisinde ortalama AR-GE yoğunluğu $\%$ 6,4'tür. En büyük beş hissedarın sermaye payı ise \%74,4'tür. Bu durum BİST firmalarının büyük bir kısmının aile şirketlerinden oluşması, sermayenin belli bir kesimde, aile içinde ve yönetim kurulunda toplanması ile açıklanabilir. Kurumsal yatırımcı sahipliği \%24,7 ve yabancı yatırımcı sahipliği ise \%7,5'tir. Gelişmiş ülkelere göre gerek kurumsal yatırımcı sahipliğinin gerekse yabancı yatırımcı sahipliğinin düşük seviyelerde kaldığı söylenebilir. 
Tablo 3: T-Testi Sonuçları

\begin{tabular}{|c|c|c|c|c|c|c|}
\hline & $\begin{array}{l}\text { AR-GE } \\
\text { Harcamaları }\end{array}$ & $\begin{array}{c}\text { Gözlem } \\
\text { Sayısı }\end{array}$ & Ort. & $\begin{array}{c}\text { Std. } \\
\text { Sapma }\end{array}$ & $\begin{array}{l}\text { Ortalama } \\
\text { Farklılığı }\end{array}$ & $\begin{array}{c}\text { Anlamlılık } \\
\text { (Sig.) }\end{array}$ \\
\hline \multicolumn{7}{|c|}{ Değişkenler } \\
\hline \multirow{2}{*}{ SPAY } & AR-GE Olmayanlar & 325 & 0,71 & 0,180 & \multirow{2}{*}{0,004} & \multirow{2}{*}{0,697} \\
\hline & AR-GE Olanlar & 459 & 0,71 & 0,169 & & \\
\hline \multirow{2}{*}{ KPAY } & AR-GE Olmayanlar & 325 & 0,24 & 0,244 & \multirow{2}{*}{$-0,007$} & \multirow{2}{*}{0,649} \\
\hline & AR-GE Olanlar & 459 & 0,25 & 0,194 & & \\
\hline \multirow{2}{*}{ YPAY } & AR-GE Olmayanlar & 325 & 0,09 & 0,198 & \multirow{2}{*}{0,027} & \multirow{2}{*}{0,018} \\
\hline & AR-GE Olanlar & 459 & 0,06 & 0,123 & & \\
\hline \multirow{2}{*}{ BORC } & AR-GE Olmayanlar & 325 & 0,39 & 0,207 & \multirow{2}{*}{$-0,049$} & \multirow{2}{*}{0,001} \\
\hline & AR-GE Olanlar & 459 & 0,44 & 0,215 & & \\
\hline \multirow{2}{*}{ BUYUK } & AR-GE Olmayanlar & 325 & 19,44 & 1,362 & \multirow{2}{*}{$-0,596$} & \multirow{2}{*}{$\mathbf{0 , 0 0 0}$} \\
\hline & AR-GE Olanlar & 459 & 20,04 & 1,356 & & \\
\hline \multirow{2}{*}{ YAS } & AR-GE Olmayanlar & 325 & 40,48 & 11,79 & \multirow{2}{*}{$-0,55$} & \multirow{2}{*}{0,514} \\
\hline & AR-GE Olanlar & 459 & 41,03 & 11,47 & & \\
\hline \multirow{2}{*}{ KAR } & AR-GE Olmayanlar & 325 & 0,04 & 0,105 & \multirow{2}{*}{0,000} & \multirow{2}{*}{0,998} \\
\hline & AR-GE Olanlar & 459 & 0,04 & 0,083 & & \\
\hline \multirow{2}{*}{ DURAN } & AR-GE Olmayanlar & 325 & 0,52 & 0,197 & \multirow{2}{*}{0,077} & \multirow{2}{*}{0,000} \\
\hline & AR-GE Olanlar & 459 & 0,44 & 0,160 & & \\
\hline \multirow{2}{*}{ STOK } & AR-GE Olmayanlar & 325 & 0,14 & 0,116 & \multirow{2}{*}{$-0,018$} & \multirow{2}{*}{0,010} \\
\hline & AR-GE Olanlar & 459 & 0,15 & 0,082 & & \\
\hline
\end{tabular}

Tablo 3'te AR-GE harcaması yapan firmalar ve AR-GE harcaması yapmayan firmalar olarak iki gruba ayrılmış ve söz konusu iki grubun sahiplik yapısı ve kontrol değişkenleri açısından bir farklılığın olup olmadığı tespit edilmiştir. Araştırmada kullanılan sahiplik yapısı değişkenleri açısından yabancı yatırımcı sahipliğinin bahsedilen iki grup arasında istatistiksel olarak anlamlı bir farklılık vardır. AR-GE harcaması yapan firmaların $(\% 6,4)$ AR-GE harcaması yapmayan firmalara $(\% 9,1)$ göre yabancı yatırımcı sahipliği daha düşüktür. Söz konusu iki grup arasında sermaye yoğunlaşması ve kurumsal yatırımcı sahipliği açısından istatistiksel olarak anlamlı bir farklılık yoktur. Bununla birlikte AR-GE harcaması yapanlar ile yapmayanlar arasında kaldıraç oranı, firma büyüklüğü, duran varlık ve stok yoğunlu açısından istatistiksel olarak anlamlı bir farklılık vardır. 
Tablo 4: Korelasyon Tablosu

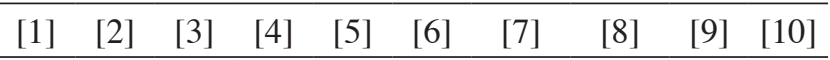

[1]AR-GE Yoğunluğu

[2]Serm. Yap. Yoğunlaşması $\quad, 02 \quad-$

[3]Kurumsal Yatırımcı Sahipliği $\quad 00 \quad 21 \quad-$

[4]Yabancı Yatırımcı Sahipliği $\quad-, 05 \quad, 16 \quad, 56 \quad-$

\begin{tabular}{lcccccccccccc}
\hline [5]Borç Yapısı &, 10 &,- 12 &, 16 &, 25 & - & & & & & \\
\hline [6]Firma Büyüklü̆ğü &, 19 &, 19 &, 00 &, 03 &, 10 & - & & & & \\
\hline [7]Firma Yaşı &,- 06 &, 27 &,- 05 &,- 00 &,- 03 &, 19 & - & & & \\
\hline [8]Firma Karlılı̆̆ı &, 00 &, 10 &,- 23 &,- 17 &,- 41 &, 12 &, 10 & - & & \\
\hline [9]Duran Varlık Yoğunluğu &,- 15 &, 02 &, 01 &,- 07 &,- 20 &, 23 &, 016 &,- 17 & - & \\
\hline [10]Stok Yoğunluğu &,- 03 &,- 11 &,- 01 &, 08 &, 24 &,- 24 &,- 038 &,- 059 &,- 51 & - \\
\hline
\end{tabular}

Tablo 4'te değişkenler arasındaki ilişkiyi gösteren korelasyon tablosu gösterilmiştir. Korelasyon sonuçları incelendiğinde AR-GE yoğunluğu ile yabancı yatırımcı sahipliği, firma yaşı, duran varlık ve stok yoğunluğu arasında negatif bir ilişki söz konusudur. Buna karşın firma büyüklüğü ve borç yapısı ile AR-GE yoğunluğu arasında pozitif bir ilişki vardır.

\section{Tablo 5: Dirençli (Robust) Tahmin Sonuçları}

\begin{tabular}{lcccc}
\hline & Katsayı & Std. Hata & t-istatistik & P değeri \\
\hline Bağımsız Değişkenler & & & & \\
\hline Sermaye Yapısı Yoğunlaşması & .007 & .008 & 0.92 & 0.357 \\
\hline Kurumsal Yatırımcı Sahipliği & .009 & .006 & 1.45 & 0.148 \\
\hline Yabancı Yatırımcı Sahipliği & -.038 & .006 & -5.69 & 0.000 \\
\hline Borç Yapısı & .005 & .009 & 2.57 & 0.046 \\
\hline Firma Büyüklü̆̆̈̈ & .009 & .001 & 7.95 & 0.000 \\
\hline Firma Yaşı & -.0004 & .000 & -15.84 & 0.000 \\
\hline Firma Karlı̆ı̆ı & -.042 & .020 & -0.21 & 0.350 \\
\hline Duran Varlık Yoğunluğu & -.075 & .010 & -7.54 & 0.000 \\
\hline Stok Yoğunluğu & -.04 & .011 & -3.44 & 0.001 \\
\hline Sabit & -.103 & .012 & -8.08 & 0.000 \\
\hline$R^{2}$ & \multicolumn{5}{c}{0.1155} \\
\hline
\end{tabular}

Tablo 5'de Robust (Dirençli) tahmincisinin sonuçları gösterilmiştir. Modellerin sonuçları incelendiğinde AR-GE yoğunluğu ile yabancı yatırımcı sahipliği arasında negatif 
bir ilişki olduğu görülmektedir. Yabancı yatırımcı sahipliğinin AR-GE harcamalarına negatif bir etki yapmaktadır. Sermaye yoğunlaşması ve kurumsal yatırımcı sahipliği ile AR-GE yoğunluğu arasında istatistiksel olarak anlamlı bir ilişli yoktur. Başka bir ifade ile sermayenin belirli kişi veya gruplarda yoğunlaşması ve bir firmada kurumsal yatırımcıların varlığ GE harcamalarına etki yapmamaktadır. Sonuç olarak $\mathrm{H}_{3}$ hipotezi kabul edilmekte ve $\mathrm{H}_{1}$ ve $\mathrm{H}_{2}$ hipotezleri reddedilmiştir.

Kontrol değişkenler incelendiğinde firmaların borç yapısı ve büyüklüğü ile ARGE harcamaları arasında pozitif ve istatistiksel olarak oldukça anlamlı bir ilişki olduğu anlaşılmaktadır. Varlıklar içerisinde yabancı kaynaklar arttıkça ve firmaların varlıkları büyüdükçe, faaliyet giderleri -içerisinde AR-GE yoğunluğu artmaktadır. Diğer kontrol değişkenler olan firma yaşı, duran varlık ve stok yoğunluğu ile AR-GE harcamaları arasında negatif bir ilişki vardır. Firma karlılığı ile AR-GE harcamaları arasında ise istatistiksel olarak anlamlı bir ilişki yoktur.

\section{Sonuç}

Bu araştırmada sahiplik yapısının başka bir ifade ile sahiplik yoğunlaşmasının, kurumsal yatırımcı sahipliğinin ve yabancı yatırımcı sahipliğinin AR-GE harcamaları üzerindeki etkisi tespit edilmiştir. Ayrıca firma büyüklüğü, yaşı, borç seviyesi, duran varlık ve stok seviyesi ile AR-GE harcamaları arasındaki ilişki de ortaya çıkarılmıştır. Çalışmada 2009-2015 yılları arasında BİST Sınai Endeksi'nde 112 firmanın verileri kullanılmıştır.

T-testi sonuçlarında; yabancı yatırımcı sahipliğinin AR-GE harcaması yapan firmaların AR-GE harcaması yapmayan firmalara göre yabancı yatırımcı sahipliği daha düşüktür. Benzer bir şekilde dirençli tahmincinin sonuçlarında ise; AR-GE harcamaları ile yabancı yatırımcı sahipliği arasında negatif bir ilişki tespit edilmiş ve bu ilişkiyi korelasyon analizi de desteklemektedir. Uluslararası yenilik süreçlerinin çokuluslu şirket ile yerel ortak arasındaki potansiyel işbirliği tarafından belirlenmektedir. Bu durum AR-GE faaliyetlerinde önemli teknolojik varlıklar ve işbirliği olmaması durumunda, çok uluslu bir şirket AR-GE faaliyetlerini kendi ülkesinde yoğunlaştırmayı tercih etmesi ile ilişkilendirilebilir. Gelişmekte olan Türkiye, çok uluslu şirketler için önemli teknolojik varlıklar veya yenilikçi işbirliği sunma konusunda kısmen daha az yetenekli olduğu söylenebilmektedir. Bu durumda yabancı yatırımcılar kendi ana ülkelerindeki ve/veya diğer gelişmiş ekonomilerdeki teknolojik avantajları kullanacaklardır. Ayrıca bu durum; özellikle imalat sanayi işletmeleri açısından çok uluslu bir şirketin ev sahibi pazar için yeni ürün tasarlamaktan çok uyarlanabilir yeniliğe yatırım yaptığını da göstermektedir.

AR-GE harcamaları ile sermaye yoğunlaşması ve kurumsal yatırımcı sahipliği arasında olarak anlamlı bir ilişli belirlenmemiştir. Başka bir ifade ile sermayenin belirli kişi veya gruplarda yoğunlaşması ve bir firma kurumsal yatırımcıların varlığg AR-GE harcamalarını etkilememektedir. Ayrıca firmaların kaldıraç oranı ve toplam varlıkları ile AR-GE harcamaları arasında pozitif ve istatistiksel olarak oldukça anlamlı bir ilişki olduğu anlaşılmaktadır. Varlıklar içerisinde yabancı kaynaklar arttıkça ve firmaların varlıkları büyüdükçe faaliyet giderleri -içerisinde AR-GE yoğunluğu artmaktadır. Kaldıraç etkisinden daha fazla yararlanan firmalar ve ölçek ekonomisinin olumlu etkisiyle birlikte daha büyük firmalar AR-GE 
harcamalarına daha fazla yatırım yapmaktadırlar. Diğer kontrol değişkenler olan duran varlık ve stok yoğunluğu ile AR-GE harcamaları arasında negatif bir ilişki vardır. Bu durum hazır değerleri veya serbest nakit akışı daha fazla olan firmaların AR-GE harcamalarını daha fazla yapmasıyla buna karşın nakit sıkıntısı çeken firmaların ise kısmen daha az AR-GE harcaması yapmasıyla ilişkilendirilebilir.

\section{Kaynakça}

Abrahams, T., \& Sidhu, B. K. (1998). The role of R\&D capitalisations in firm valuation and performance measurement. Australian Journal of Management, 23(2), 169-183.

Ahmed, K., \& Jinan, M. (2011). The association between research and development expenditure and firm performance: Testing a life cycle hypothesis. International Journal of Accounting, Auditing and Performance Evaluation, 7(4), 267-286.

Aghion, P., Van Reenen, J., \& Zingales, L. (2013). Innovation and institutional ownership. The American Economic Review, 103(1), 277-304.

Al-Horani, A., Pope, P. F., \& Stark, A. W. (2003). Research and development activity and expected returns in the United Kingdom. European Finance Review, 7(1), 27-46.

Andersson, J., Nordwall, J., \& Salomonsson, D. (2005). The link between ownership structure and firm performance: Evidence from Sweden's listed companies. https://gupea.ub.gu. se/bitstream/2077/2266/1/gbs_thesis_37.pdf, 02.02.2017.

Barnhart, S. W., \& Rosenstein, S. (1998). Board composition, managerial ownership, and firm performance: An empirical analysis. Financial Review, 33(4), 1-16.

Baysinger, B. D., Kosnik, R. D., \& Turk, T. A. (1991). Effects of board and ownership structure on corporate R\&D strategy. Academy of Management Journal, 34(1), 205-214.

Bhagat, S., \& Black, B. (2001). The non-correlation between board independence and longterm firm performance. Journal of Corporation Law, 27, 231-274.

Beiner, S., Drobetz, W., Schmid, M. M., \& Zimmermann, H. (2006). An integrated framework of corporate governance and firm valuation. European Financial Management, 12(2), 249-283.

Brickley, J. A., Lease, R. C., \& Smith, C. W. (1988). Ownership structure and voting on antitakeover amendments. Journal of Financial Economics, 20, 267-291.

Brossard, O., Lavigne, S., \& Sakinc, M. E. (2013). Ownership structures and R\&D in Europe: The good institutional investors, the bad and ugly impatient shareholders. Industrial and Corporate Change, 22(4), 1031-1068.

Buckley, P. J., Wang, C., \& Clegg, J. (2007). The impact of foreign ownership, local ownership and industry characteristics on spillover benefits from foreign direct investment in China. International Business Review, 16(2), 142-158.

Bushee, B. J. (1998). The influence of institutional investors on myopic R\&D investment behavior. Accounting Review, 305-333.

Chambers, D., Jennings, R., \& Thompson, R. B. (2002). Excess returns to R\&D-intensive firms. Review of Accounting Studies, 7(2-3), 133-158. 
Chan, L. K., Lakonishok, J., \& Sougiannis, T. (2001). The stock market valuation of research and development expenditures. The Journal of Finance, 56(6), 2431-2456.

Chauvin, K. W., \& Hirschey, M. (1993). Advertising, R\&D expenditures and the market value of the firm. Financial management, 22(4), 128-140.

Cheng, J. L., \& Bolon, D. S. (1993). The management of multinational R\&D: A neglected topic in international business research. Journal of International Business Studies, 24(1), $1-18$.

Cheung, K. Y., \& Ping, L. (2004). Spillover effects of FDI on innovation in China: Evidence from the provincial data. China Economic Review, 15(1), 25-44.

Cho, D. S., \& Kim, J. (2007). Outside directors, ownership structure and firm profitability in Korea. Corporate Governance: An International Review, 15(2), 239-250.

Choi, S. B., Lee, S. H., \& Williams, C. (2011). Ownership and firm innovation in a transition economy: Evidence from China. Research Policy, 40(3), 441-452.

De Mello Jr, L. R. (1997). Foreign direct investment in developing countries and growth: A selective survey. The Journal of Development Studies, 34(1), 1-34.

Eberhart, A. C., Maxwell, W. F., \& Siddique, A. R. (2004). An examination of long-term abnormal stock returns and operating performance following $\mathrm{R} \& \mathrm{D}$ increases. The Journal of Finance, 59(2), 623-650.

Elsayed, K. (2011). Board size and corporate performance: The missing role of board leadership structure. Journal of Management \& Governance, 15(3), 415-446.

Eng, L. L., \& Shackell, M. (2001). The implications of long-term performance plans and institutional ownership for firms' research and development (R\&D) investments. Journal of Accounting, Auditing \& Finance, 16(2), 117-139.

Fauzi, F., \& Locke, S. (2012). Board structure, ownership structure and firm performance: A study of New Zealand listed-firms.

Gassmann, O., \& Zedtwitz, M. (2003). Trends and determinants of managing virtual R\&D teams. $R \& D$ Management, 33(3), 243-262.

Ghaffar, A., \& Khan, W. A. (2014). Impact of research and Development on Firm Performance. International Journal of Accounting and Financial Reporting, 4(1), 357.

Graves, S. B. (1988). Institutional ownership and corporate R\&D in the computer industry. Academy of Management Journal, 31(2), 417-428.

Graves, S. B., \& Waddock, S. A. (1990). Institutional ownership and control: Implications for long-term corporate strategy. The Executive, 4(1), 75-83.

Hill, C. W., \& Snell, S. A. (1988). External control, corporate strategy, and firm performance in research intensive industries. Strategic Management Journal, 9(6), 577-590.

Holderness Clifford, G., Kroszner Randall, S., \& Sheehan Dennis, P. (1999). Were the good old days that good? Evolution of managerial stock ownership and corporate governance since the great depression. Journal of Finance, 54, 353-384.

Krasnikov, A., \& Jayachandran, S. (2008). The relative impact of marketing, research-anddevelopment, and operations capabilities on firm performance. Journal of Marketing, 72(4), 1-11. 
Kochhar, R., \& David, P. (1996). Institutional investors and firm innovation: A test of competing hypotheses. Strategic Management Journal, 73-84.

Kouznetsov, P., \& Muravyev, A. (2001). Ownership structure and firm performance in Russia: The case of blue chips of the stock market (No. 01-10e). EERC Research Network, Russia and CIS.

Lev, B., Sarath, B., \& Sougiannis, T. (2005). R\&D reporting biases and their consequences. Contemporary Accounting Research, 22(4), 977-1026.

Mak, Y. T., \& Kusnadi, Y. (2005). Size really matters: Further evidence on the negative relationship between board size and firm value. Pacific-Basin Finance Journal, 13(3), 301-318.

Minetti, R., Murro, P., \& Paiella, M. (2012). Ownership structure, governance, and innovation: Evidence from Italy.https://editorialexpress.com/cgi-bin/conference/download.cgi?db_ name=ICEEE5\&paper_id=160, 01.02.2017.

Molas-Gallart, J., \& Tang, P. (2006). Ownership matters: Intellectual property, privatization and innovation. Research Policy, 35(2), 200-212.

O'Sullivan, M. (2000). The innovative enterprise and corporate governance. Cambridge Journal of Economics, 24(4), 393-416.

Oxelheim, L., \& Randøy, T. (2003). The impact of foreign board membership on firm value. Journal of Banking \& Finance, 27(12), 2369-2392.

Pearce, R. (1994). The internationalisation of research and development by multinational enterprises and the transfer sciences. Empirica, 21(3), 297-311.

Porta, R., Lopez de Silanes, F., \& Shleifer, A. (1999). Corporate ownership around the world. The Journal of Finance, 54(2), 471-517.

Porter, M. E. (1991). Capital disadvantage: America's failing capital investment system. Harvard Business Review, 70(5), 65-82.

Rossi, F., \& Cebula, R. J. (2015). Ownership structure and R\&D: An empirical analysis of Italian listed companies. PSL Quarterly Review, 68(275), 297-325.

Sharma, C. (2012). R\&D and firm performance: Evidence from the Indian pharmaceutical industry. Journal of the Asia Pacific Economy, 17(2), 332-342.

Sougiannis, T. (1994). The accounting based valuation of corporate. R\&D. Accounting review, 69(1), 44-68.

Sueyoshi, T., Goto, M., \& Omi, Y. (2010). Corporate governance and firm performance: Evidence from Japanese manufacturing industries after the lost decade. European Journal of Operational Research, 203(3), 724-736.

Teng, D., \& Jingtao, Y. (2014).Ownership, R\&D intensity and performance: Evidence from transitional China. http://mbsportal.bl.uk/taster/subjareas/strategy/bam2014/strategy/ full/178364contribution200.pdf, 01.02.2017.

Vo, D., \& Phan, T. (2013). Corporate governance and firm performance: Empirical evidence from Vietnam. Journal of Economic Development, 62-78.

Wang, Y., \& Clift, B. (2009). Is there a "business case" for board diversity?. Pacific Accounting Review, 21(2), 88-103. 
Yan Lam, T., \& Kam Lee, S. (2008). CEO duality and firm performance: Evidence from Hong Kong. Corporate Governance: The international Journal of Business in Society, 8(3), 299-316.

Zahra, S. A., \& Covin, J. G. (1995). Contextual influences on the corporate entrepreneurshipperformance relationship: A longitudinal analysis. Journal of Business Venturing, 10(1), 43-58.

Zhang, Y., Li, H., Hitt, M. A., \& Cui, G. (2007). R\&D intensity and international joint venture performance in an emerging market: Moderating effects of market focus and ownership structure. Journal of International Business Studies, 38(6), 944-960.

Zeng, T., \& Lin, H. C. (2011). Ownership structure and R\&D spending: Evidence from China's listed firms. Chinese Management Studies, 5(1), 82-93. 
